\title{
An Analysis of Bitcoin Price Based on VEC Model
}

\author{
Junpeng Wang ${ }^{1,{ }^{*}}$, Yubo Xue ${ }^{1}$ and Minghao Liu ${ }^{1}$ \\ ${ }^{1}$ School of economics and management, Beijing University of Posts and Telecommunications, \\ Beijing, China \\ *wangjunpeng2013@hotmail.com
}

\begin{abstract}
As the world's first completely decentralized digital payment system, the emergence of bitcoin represents a revolutionary phenomenon in financial markets. This paper mainly studies the fluctuations of bitcoin price and discusses weather digital currencies represented by bitcoin have the potential to invest. Cointegration analysis and VEC (Vector Error Correction) Model have been performed to demonstrate the relationship between bitcoin price and some variables including stock price index, oil price and daily trading volume of bitcoin. The empirical research indicates that there is long-term equilibrium and short-term dynamic relationship among the four factors. The short run analysis reveals that oil price and bitcoin trading volume have little influence on bitcoin price while stock price index has relatively larger impact on it. In the long run, stock price index and oil price have a negative effect on bitcoin price. On the contrary, the value of bitcoin is positively affected by daily trading volume.
\end{abstract}

Keywords: Bitcoin, Price fluctuation, Cointegration analysis, VEC model, Investment value.

\section{Introduction}

Bitcoin, introduced in 2009 by Satoshi Nakamoto, is a digital currency that emerged as a peer-to-peer payment system. It is the combination of modern cryptology and communications technology and can meet the need of decentralization, controlling of money supply, estimating the amount of money in circulation and reducing the inflation. Basically, bitcoin has the functions and properties of currency, but the academic community has not yet formed a consensus on whether it belongs to real currency[1].

Bitcoin was pretty cheap at its birth, only about 5 cents per bitcoin. But with the promotion of its influence around the world, its price boomed. In 2013, America government published the Personal virtual currency regulations, which admitted the legal status of bitcoin, making bitcoin price raised from $\$ 13$ earlier that year to more than $\$ 1000$. In October 2013, influenced by the global "Bitcoin Hot", the demand of bitcoin in China increased. The relevant policies and regulatory laws failed to contain the crazy investment sentiment of investors in China, which further raised its price, the price soared to a historic record of $\$ 1151$. On Sep.15th, 2015, the ETF management company Ark Invest's Internet theme funds purchased bitcoin assets - Bitcoin Investment Trust (GBTC). It was the first ETF including bitcoin assets in the world [2].

Bitcoin has been endued with significant investment and speculative value due to its rapid appreciation and depreciation, which has caught the attention of governments and investors. In the short term, the price fluctuations of bitcoin are negligible in the case of global economic and financial system and there is no need for financial institutions to worry about its impacts on financial markets. But in the long term, bitcoin or similar digital currencies is the out-and-out financial innovation in the context of the current Internet financial times, its development will have a profound effect on future innovation direction of investment and monetary system [3].

This paper mainly studies the price fluctuations of bitcoin and discusses weather digital currencies represented by bitcoin have the potential and value to invest. 


\section{Literature review}

The innovative way of issuing and the violent price fluctuation of bitcoin have aroused wide concern in both the academic field and the industrial field. Paul Krugman (2013) believes that bitcoin will fall into a liquidity trap caused by the fixed supply of bitcoin in the long run. He claims that as the price of bitcoin rises, the amount of bitcoin in circulation will decrease, resulting in deflation, people have a strong incentive to hoard bitcoin rather than spend it [4]. Buchholz et al. (2012) conclude that bitcoin price is mainly driven by its supply and demand in the market, the demand for bitcoin is mainly determined by the value of it as a medium of exchange (the value of the upcoming exchange) [5].Joseph Wang (2014) argues that long-run increases or decreases in the price of bitcoin will not influenced by the transactional use of bitcoin but rather by external factors which change the likelihood that a given bitcoin will be saved and bitcoin is prone to sudden changes in price due to news events and public expectations, He asserts that bitcoin will not fall victim to a liquidity trap due to the convertibility between bitcoin and fiat money [6].

Yermack (2013) claims that bitcoin tends to be an investment asset or speculative tool rather than a currency. Bitcoin price is highly correlated with its own trading characteristics, has no correlation with classical currencies, and is not influenced by macroeconomic events. Therefore, there is no chance for risk management purposes with bitcoin and it's difficult to hold positions to hedge for bitcoin holders [7]. Hanley (2013) argues that the value of bitcoin floats against other currencies as a pure market valuation with no fundamental value to support it. Woo, et al. (2013) proposes that bitcoin may have some fair value due to its money-like properties as a medium of exchange and a store of value, but without any other underlying basis [8]. Bouoiyour \& Selmi (2014) attempt to describe bitcoin value by regressing its market price against a number of independent variables including the market price of gold, occurrences of the word 'bitcoin' in web searches, the velocity of bitcoin and so on. The variables regressed were not statistically significant at the $5 \%$ or better level of significance. Lags on the price of bitcoin itself were found to explained most of its volatility, indicating that some other variables may account for the fluctuations of bitcoin price [9].

This article aims to demonstrate the effect of several factors on the fluctuations of bitcoin price and the intrinsic mechanism through empirical research on the basis of these studies.

\section{Econometric method and data process}

\subsection{Model selection}

When describing the dynamic effects of the interaction and disturbance between the non-stationary time series, the cointegration test and the vector error correction (VEC) model are suitable technical methods. Cointegration test is to determine whether there is a stable linear combination between a collection of non-stationary time series. If there exist, the linear combination is called the cointegration equation, which reflects the long-run equilibrium relationship between these non-stationary variables. Johansen developed the cointegration test of non-stationary and multivariate time series on the basis of VAR. He established VAR model with cointegration constraints, which is known as vector error correction (VEC) model, to describe the long-run equilibrium relationship and short-term deviation and reveal the dynamic attribute of the system [10]. Therefore, a VEC model is established to investigate the existence of long-term relationship between bitcoin price and some fundamental variables.

\subsection{Factors influencing bitcoin price}

Bitcoin is still considered as a special commodity at the moment, so it is restricted by the relationship between supply and demand. Its supply mold has been strictly set at its birth. In the long run, the slope of supply curve will increase with the difficulty of mining increases, which will push up the price [11]. The development degree of macroeconomic and finance can influence the value of bitcoin through various channels from many aspects. We will analyze the impact of several variables to bitcoin price. 
(1) Stock price Index

Stock price index can reflect the development degree of macroeconomic and finance. Sound macroeconomic and financial environment may promote the use of bitcoin in transactions and exchanges, which has a positive impact on bitcoin price. On the other hand, the stock price index is likely to be negatively correlated with the price of bitcoin. When the economy is prosperous, investors tend to make profit from the stock market, so during the bull period, the price of other investment targets will fall. Conversely, when the economy is in recession, the stock market is in the doldrums, the price of other investment targets will increase.

(2) Crude Oil Price

Crude oil price has a close relationship with investors' behaviors. As oil is an important strategic and economic resource, its price is an important indicator to reflect the world economy development. The rise of oil price tends to incur inflation, when oil price rises, investors are likely to invest in alternatives. When investors have inflation expectations, some of them will choose bitcoin to hedge. In addition, the volatility in oil price may affect the development of the world economy, which may influence bitcoin price indirectly

(3) Trading Volume

Rational expectations theory proposes that economic individuals' expectations of future events are rational. When judging the economic situations, they try their best to obtain the most complete information and use all available knowledge of statistics, history and relationships between economic variables. After careful thinking and analysis, they will make predictions of future economic conditions. However, investors in the market may not be entirely rational, constant news of true and false in the market will make different investors have different expectations for the future of bitcoin, the different expectations may reflect in the trading volume and affect the price of bitcoin.

\subsection{Variable selection}

It is since 2011 that bitcoin price began to fluctuate significantly and attract increasing attention. So the sample period we choose is from January 2011 to April 2016, too much noise exists in the data before 2011 as a result of the small trading volume. The data relevant to bitcoin comes from Blockchain.info, other data comes from Wind.

As there is no financial product related to bitcoin in the market and dollar is a major foreign exchange currency of bitcoin, we use the exchange rate of bitcoin and dollar to represent the price of bitcoin.

When measuring the stock price index, we adopt the Dow Jones industrial average index, which is an important indicator of the stock market. When measuring the crude oil prices, we choose the WTI crude oil price of the New York Mercantile Exchange, which can reflect the economic power of the United States in the world.

Logarithmic treatment to the bitcoin price, the stock price index, the oil price and the daily trading volume is conducted. We use $\ln$ to denote the processed data and d denote the first order difference of the processed data. (i.e. lnbitp represents the natural logarithm of bitcoin price, dlnbitp represents the first order difference of the natural logarithm series) In this way, the cointegration relationship will not be destroyed and the heteroscedasticity can be eliminated in the original sequences.

\section{Empirical research}

\subsection{Stationarity test of variables}

Testing the stationarity of the variables is the premise of the cointegration test and the establishment of the model, otherwise spurious regression may occur. We will use the ADF test to test the stationarity of each time series initially.

Table 1 shows that the original variable sequences lnbitp, lndow, lnoil and lnvol are not stable at the significant level of 5\%, but the sequences after the first order difference are stable at the level of $5 \%$, that is to say, they are first order nonstationary time series I (1). As the vector autoregression model requires stationary time series data, we will adopt the first order difference of each variable for econometric analysis. 
Table 1. ADF unit root test of variable sequence

\begin{tabular}{|c|c|c|c|c|c|c|}
\hline \multirow{2}{*}{ Variable } & \multirow{2}{*}{ Test form } & \multirow{2}{*}{ ADF statistic } & \multicolumn{3}{|c|}{ Critical value } & \multirow{2}{*}{$\begin{array}{c}\mathrm{p} \\
\text { value }\end{array}$} \\
\cline { 4 - 6 } & & & $1 \%$ & $5 \%$ & $10 \%$ & -2.567870 \\
\hline Inbitp & $(\mathrm{c}, 0,5)$ & -2.524680 & -3.435080 & -2.863510 & -2.5698 \\
\hline Indow & $(\mathrm{c}, \mathrm{t}, 5)$ & -2.597450 & -3.965000 & -3.413210 & -3.128620 & 0.2816 \\
\hline Inoil & $(\mathrm{c}, \mathrm{t}, 1)$ & -1.870880 & -3.964980 & -3.413200 & -3.128620 & 0.6690 \\
\hline Invol & $(\mathrm{c}, 0,4)$ & -2.541773 & -3.435082 & -2.863517 & -2.567872 & 0.1058 \\
\hline dlnbitp & $(\mathrm{c}, 0,4)$ & -14.906900 & -3.435080 & -2.863510 & -2.567870 & 0.0000 \\
\hline dlndow & $(\mathrm{c}, \mathrm{t}, 4)$ & -18.256000 & -3.965000 & -3.413210 & -3.128620 & 0.0000 \\
\hline dlnoil & $(\mathrm{c}, \mathrm{t}, 0)$ & -38.527400 & -3.964980 & -3.413200 & -3.128620 & 0.0000 \\
\hline dlnvol & $(\mathrm{c}, 0,6)$ & -18.251200 & -3.435090 & -2.863520 & -2.567870 & 0.0000 \\
\hline
\end{tabular}

Note: In the ADF test form (c, t, k), c denotes whether there is an intercept or not, t denotes whether there is a trend or not, $\mathrm{k}$ denotes the lag order, $\mathrm{D}$ denotes the first order difference of original variable sequences.

\subsection{Cointegration test and analysis}

The four variables are stationary series after the first order difference, so the Johansen method can be used for cointegration test. Cointegration relationship among variables can be determined through trace statistic and the maximum eigenvalue likelihood ratio statistic. Before cointegration test, it is necessary to determine the lag order of the VAR model. The lag order should not only ensure a reasonable degree of freedom to make the parameters of the model have strong explanatory power, but also eliminate the autocorrelation of error term. Let $X_{t}=\left(\operatorname{lnbit} p_{t}\right.$, lndow $\left.w_{t}, l n o i l_{t}, \operatorname{lnvol}_{t}\right)$, constituting a column vector and set the VAR model. Table 2 shows the information criteria of the lag order.

Table 2. Information criteria of lag order

\begin{tabular}{|r|r|r|r|r|r|c|}
\hline \multicolumn{1}{|c|}{ Lag } & \multicolumn{1}{c|}{ LogL } & \multicolumn{1}{c|}{ LR } & FPE & \multicolumn{1}{c|}{ AIC } & \multicolumn{1}{c|}{ SC } & \multicolumn{1}{c|}{ HQ } \\
\hline 0 & -2248.41 & NA & 0.00035 & 3.397307 & 3.412963 & 3.403176 \\
\hline 1 & 9966.94 & 24338.59 & $3.58 \mathrm{E}-12$ & -15.0029 & -14.9246 & -14.9735 \\
\hline 2 & 10051.9 & $168.7691^{*}$ & $3.2 \mathrm{e}-12^{*}$ & $-15.106^{*}$ & $-14.966^{*}$ & $-15.054^{*}$ \\
\hline
\end{tabular}

Note: * represents the selected lag order from each information criteria.

The result of the above information criteria shows that a second order delayed of VAR model fits well, the residual error sequence is stable and no autocorrelation exists, so VAR (2) is the optimal model.

After determining the optimal lag order of the VAR model, we use Johansen cointegration test to determine whether there is a long-term and stable relationship between bitcoin price, stock price index, oil price, and bitcoin daily trading volume. There are mainly two methods of Johansen cointegration test, trace statistic and the maximum eigenvalue likelihood ratio statistic, we adopt Johansen's trace test for multivariate cointegration. Using test model with intercept and no tendency for cointegration test of vector $Y_{t}=\left(\operatorname{lnbitp}_{t}, \operatorname{lndow}_{t}, \operatorname{lnoil}_{t}, \operatorname{lnvol}_{t}\right)$, the results are shown in the table below:

Table 3. Trace statistic test results

\begin{tabular}{|r|r|r|r|r|}
\hline $\begin{array}{c}\text { Hypothesized } \\
\text { No. of CE(s) }\end{array}$ & Eigenvalue & $\begin{array}{c}\text { Trace } \\
\text { Statistic }\end{array}$ & $\begin{array}{c}0.1 \\
\text { Critical Value }\end{array}$ & Prob. $^{* *}$ \\
\hline None & 0.015661 & 46.69571 & 44.49359 & 0.0641 \\
\hline At most 1 & 0.013571 & 25.76533 & 27.06695 & 0.1359 \\
\hline At most 2 & 0.004991 & 7.647264 & 13.42878 & 0.5039 \\
\hline At most 3 & 0.000763 & 1.012013 & 2.705545 & 0.3144 \\
\hline
\end{tabular}

The procedure starts with testing for zero cointegrating vectors and then accepts the first null hypothesis that is not rejected. As shown in Table 3, at the level of $10 \%$ significance, we reject the null hypothesis of no cointegration but fail to reject the null hypothesis of at most one cointegrating vector. Therefore, we accept that there is one cointegrating equation in the model.

Then a standardized cointegration equation can be obtained to reflect the mathematical relation between the four variables: bitcoin price, stock price index, oil price and bitcoin daily trading volume: 
Lnbitp $=-3.32759$ Lndow-1.312328Lnoil +0.773170 Lnvol

$(0.00366) \quad(0.00961) \quad(0.00439)$

The cointegration equation explains the long-term equilibrium relationship between the four variables, the value in the parentheses is the standard deviation. For each factor, the standard deviation is small, indicating that the coefficient is not significantly equal to zero. The cointegration equation shows that, in the long run, bitcoin price stock price index and the price of crude oil, and is positively related to daily trading volume. The long-term elasticity of bitcoin price to stock price index is 3.32, showing that bitcoin price is quite sensitive to stock price index. When stock index changes $1 \%$, bitcoin price changes $3.32 \%$. There is a negative relationship between the price of bitcoin and oil price, oil price rises by $1 \%$, the bitcoin price will fall by $1.32 \%$. There is a positive correlation relationship between bitcoin price and bitcoin daily trading volume, bitcoin daily trading volume rises by $1 \%$ will lead to bitcoin price rise $0.77 \%$. From the above analysis, we can see that changes in oil price and daily trading volume have little impact on bitcoin price while changes in stock price index have relatively more significant impact.

\subsection{Establishment of VEC model}

Cointegration test shows that there exists a long-term equilibrium relationship between variables, but the short-term adjustment of this equilibrium relationship and whether there is a causal relationship between the four variables should be further validated. Engle and Granger (1987) pointed out that if there is a cointegration relationship between the variables in VAR, then the vector error correction model (VECM)including error correction term EC can be established, so as to research the short-term dynamic characteristics of the model. So we use VECM to test the causal relationship between the four variables. The lag period of the VECM is the delay of the first order difference of the VAR model without restriction, so we can decide the lag order of VECM is 1.

The dynamic correction mechanism for the price of bitcoin in the short term is given below: $\mathrm{D}(\mathrm{LNBITP})=0.088161 * \mathrm{D}(\operatorname{LNBITP}(-1))-0.082221 * \mathrm{D}(\operatorname{LNDOW}(-1))+0.005101 * \mathrm{D}(\mathrm{LNOIL}(-1))-$ $0.001973 * \mathrm{D}(\mathrm{LNVOL}(-1))-0.005377 * \mathrm{ecmt}+0.005078$

Where the error correction term ecmt $=$ LNBITP(-1) -3.327591 *LNDOW(-1) -1.312328*LNOIL(-1) $+0.773170 *$ LNVOL $(-1)+17.9132635+0.088161 * \mathrm{D}(\mathrm{LNBITP}(-1))$

The VEC Model indicates that the cointegration relationship has a reverse correction effect on bitcoin price. If the bitcoin price of last period far exceeds the equilibrium constraint, error correction tends to make the bitcoin price of current period decline.

\subsection{Impulse-response functions and variance decompositions}

Impulse-response functions (IRFs) can be used to estimate the effects of an exogenous shock to a single variable on the dynamic paths of all of the variables of the system. Based on the research above, we further characterize the IRFs between the variable sequences to analyze the short-term dynamic relationship between them. We observe the shock of one unit standard deviation and the observation period is 20 .

In the short-term, a positive shock of stock price index and oil price has a positive impact on bitcoin price. As can be seen from Fig .1, the reaction of bitcoin price to the fluctuations of oil price is not obvious, but the reaction to the change of stock price index is obvious and can remain for some time. It indicates that when stock price falls, many investors tend to look for substitutes. 
Figure 1. Impulse response analysis results

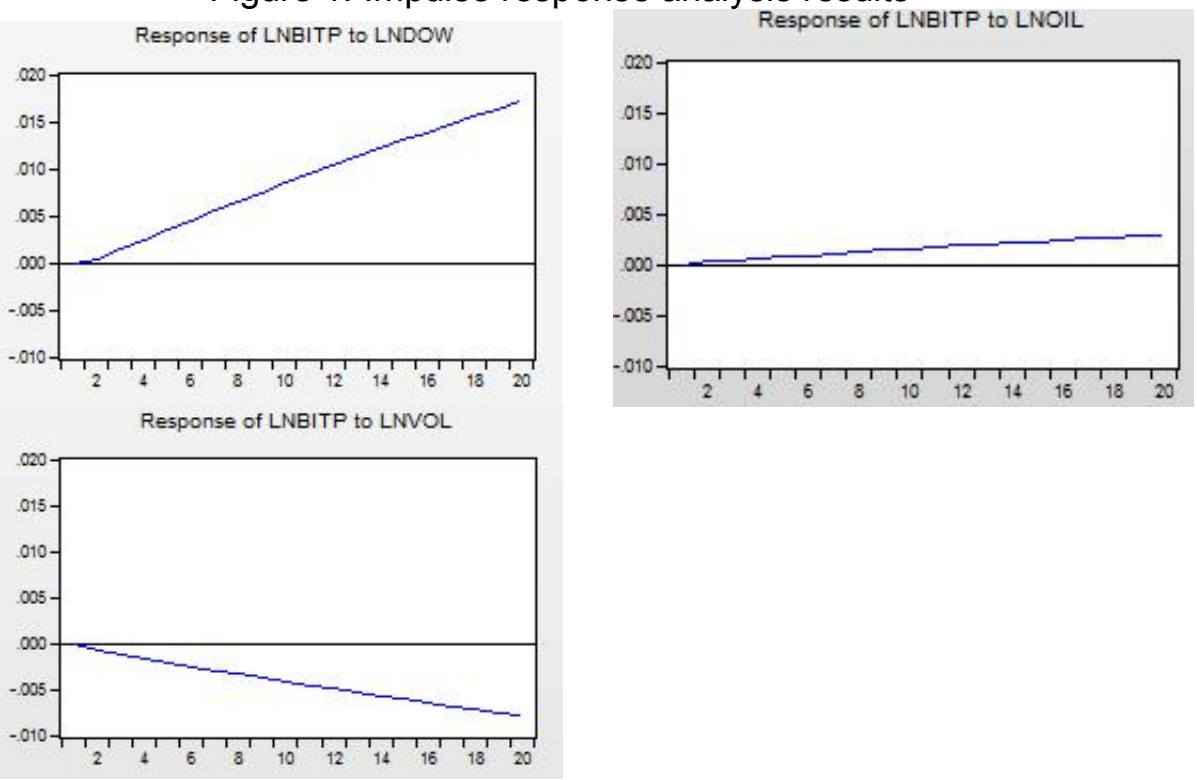

IRFs measure the dynamic marginal effects of each shock on all of the variables over time. Variance decompositions examine how important each of the shocks is as a component of the overall variance of each of the variables over time. Apply the variance decomposition to the forecast error of the equation where bitcoin price is the dependent variable and the result is basically stable after the $50^{\text {th }}$ period.

Table 5. Variance decomposition results

\begin{tabular}{|c|c|c|c|c|c|}
\hline Period & S.E. & LNBITP & LNDOW & LNVOL & LNOIL \\
\hline 50 & 0.502183 & 55.63089 & 36.51219 & 6.885217 & 0.971703 \\
\hline
\end{tabular}

Variance decomposition results show that, to the fluctuations of bitcoin price, variance contribution rate of stock price index is $36 \%$, daily trading volume is $7 \%$, oil price is $1 \%$ and the other $55 \%$ comes from bitcoin price's own standard error, which is consistent with the results of IRFs. It indicates that the transmission effect of bitcoin price itself is large, and the impact of stock index, bitcoin trading volume and oil price have minor influence on bitcoin price.

\section{Conclusion}

In this paper, $\mathrm{ADF}$ unit root test, cointegration analysis, impulse response functions and variance decompositions are adopted to construct VEC model. It mainly analyzes the influence of stock price index, oil price and daily trading volume on bitcoin price. The empirical research shows that:

1. Stock price index, oil price and bitcoin daily trading volume have a stable long-term relationship with the price of bitcoin, and in the short term, bitcoin price has the dynamic mechanism to adjust to the long-term equilibrium level.

2. Changes in oil price and daily trading volume have little impact on bitcoin price while changes in stock price index have significant impact on it.

3. Bitcoin price is negatively related with the stock price index and the oil price, but is positively related with the daily trading volume. This is mainly because when the stock index rises, investors are more willing to make profit from the stock market, thus the prices of other investment targets will decline. When the economy is in recession, the stock market is in the doldrums, many investors tend to invest hedging products, so the bitcoin price will rise. Oil price has a close relationship with investors' behaviors. It can reflect investors' inflation expectations to some extent, so it will affect bitcoin price indirectly. Generally speaking, bitcoin daily trading volume can reflect the degree of investors' attention to bitcoin, the more active the bitcoin market is, the higher the price.

Above synthesis conclusion, we believe that bitcoin is still an investment commodity or speculative tool. The high volatility of its price makes it difficult to resist inflation and people scramble to hold bitcoin is just to wait for appreciation to profit. The attitude of a number of 
governments towards bitcoin shows that future development of digital currencies like bitcoin are likely to be limited. In addition, bitcoin has exposed many security risks in the process of rapid development, accidents that bitcoin trading platform been stolen by hackers happen now and then. That is to say, future development of bitcoin faces great uncertainty.

For investors, when including bitcoin in the portfolio, it is necessary to consider the price trend, security risks and legal policies relevant to it. If the investment environment of bitcoin can be improved by legislations, bitcoin will become a legal investment product. Then people will recognize the value of bitcoin and the bitcoin investment market will move toward the rationality, which would be a good complement to the stock market.[12,13]

Acknowledgments. This research has been co-financed by Research Innovation Fund for College Students of Beijing University of Posts and Telecommunications and Special Found for Beijing Common Construction Project.

\section{References}

[1] Centralny E B. Virtual Currency Schemes. ECB,Frankfurt am Main, 2012.Surda R Economics of Bitcoin: is Bitcoin an alternative to fiat currencies and gold?, na, 2012.

[2] Briere M,Oosterlinck Szafarz A. Virtual currency, tangible return: portfolio diversification with bitcoins. Tangible Return: Portfolio Diversification with Bitcoins (September 12,2013),2013.

[3] Chey H. Theories of International Currencies and the Future of the World Monetary Orderl. Int ernational Studies Review, 2012,14(1): 51-77.

[4] Paul Krugman. Adam smith hates bitcoin, 2013.URL http://krugman.blogs.nytimes.com/2013/0 4/12/adam-smith-hates-bitcoin/. [Online; accessed 11-February-2014].

[5] Buchholz M, Delaney J,Warren J,et al. Bits and Bets, Information, Price Volatility, and Demand for Bitcoin. Economics, 2012,312.

[6] M Wang, Joseph Chen-Yu, A Simple Macroeconomic Model of Bitcoin (February 11, 2014). Av ailable at SSRN: http://ssrn.com/abstract=2394024.

[7] Yermack D. Is Bitcoin a real currency? An economic appraisal. National Bureau of Economic R esearch, 2013.

[8] Hanley, Brian P. The false premises and promises of Bitcoin. arXiv preprint arXiv:1312.2048, 2013.

[9] Bouoiyour, Jamal, and Refk Selmi. What Bitcoin Looks Like? . No. 58091. University Library of Munich, Germany, 2014.

[10] Gao,Tiemei. Econometric analysis methods and modeling. Beijing: Tsinghua University Press, 2009

[11] Yu,Jiang. Summary of Bitcoin Development. Journal of Jilin Financial Research, 2013(5):17-2 3.

[12] Guo,Di. Research on the development prospect of bitcoin. Securities \& Futures of China, Vol. 072013.

[13] Cai,Zhihong. The development, possible influence and supervision progress of digital money. Financial Development Review, 2015 (3) : 133-138. 